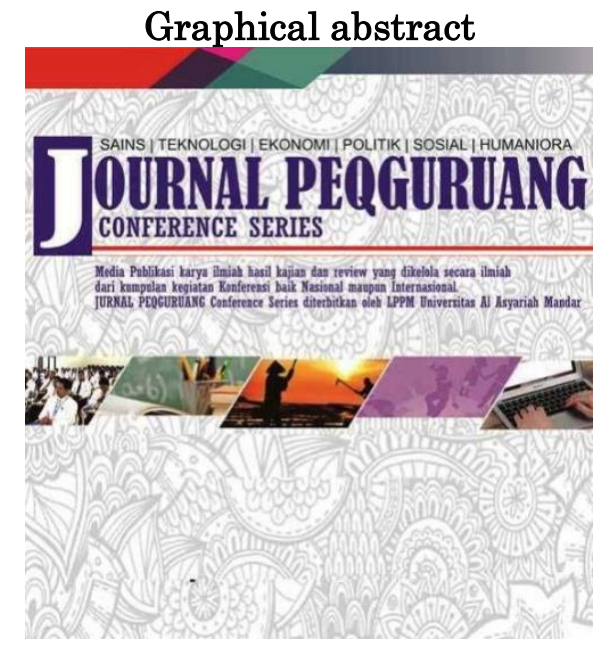

\title{
SISTEM INFORMASI PENDATAAN DAN PENILAIAN PKL (PRAKTEK KERJA LAPANGAN) MAHASISWA BERBASIS WEB
}

\author{
1*Novianti, ${ }^{2}$ A.Akhmad Qaslim, ${ }^{3}$ Ashabul Kahpi \\ Universitas Al Asyariah Mandar \\ *Corresponding author \\ evyyana33@gmail.com@
}

\begin{abstract}
Field work practice (pkl) is a form of systematic and synchronous implementation of educational programs on campus with mastery of skills programs obtained through direct work activities in the world of work to achieve a certain level of expertise. The process of registering and reporting on the implementation of the field work practice (pkl) in the information systems study program is still done manually. Based on this, the author makes a website-based job training management information system at the information systems study program, al asyariah mandar university. For system design using dfd (data flow diagram). From the results of the manufacture, that with the existence of a field work practice management information system, it is hoped that it can help students of the information systems study program in implementing field work practices.
\end{abstract}

Keywords: Complaint, Android, Community

\begin{abstract}
Abstrak
Praktek kerja lapangan (pkl) merupakan salah satu bentuk implementasi secara sistematis dan sinkron antara program pendidikan di kampus dengan program penguasaan keahlian yang diperoleh melalui kegiatan kerja secara langsung didunia kerja untuk mencapai tingkat keahlian tertentu. Proses pendaftaran dan pelaporan pelaksanaan praktek kerja lapangan (pkl) di prodi sistem informasi masih dilakukan secara manual. Berdasarkan hal tersebut penulis membuat sistem informasi manajemen praktek kerja lapangan berbasis website pada program studi sistem informasi universitas al asyariah mandar untuk pembuatan aplikasi website dibangun dengan menggunakan bahasa pemrograman html, php dan database mysol. Untuk perancangan sistem menggunakan dfd (data flow diagram). Dari hasil pembuatan tersebut, bahwa dengan adanya sistem informasi manajemen praktek kerja lapangan ini diharapkan dapat membantu mahasiswa program studi sistem informasi dalam pelaksanaan peraktek kerja lapangan.
\end{abstract}

Kata kunci: Pengaduan, Android, Masyarakat

\section{Article history}

DOI: https://dx.doi.org/10.35329/ip.v3i2.2438

Received : 22 Juli 2021 | Received in revised form : 21 Agustus 2021 | Accepted : 23 Oktober 2021 


\section{PENDAHULUAN}

Teknologi informasi terus berkembang seiring dengan kemampuan komputer untuk memberi solusi bagi permasalahan diberbagai bidang baik itu dibidang perekonomian sosial organisasi hingga bidang pendidikan. Dengan teknologi informasi memanajemeni dan pendataan informasi-informasi akan lebih efisien waktu dan tenaga karena dilakukan secara digital, tidak terlalu banyak kegiatan yang memerlukan dokumendokumen kertas. Teknologi informasi yang bersifat online pada saat ini sudah banyak digunakan dalam berbagai aktifitas karena dengan adanya sistem yang bersifat online informasi-informasi lebih cepat didapat dan direspon.(Makmur, 2019)

Perkembangan teknologi yang semakin kompleks Untuk pelaksanaan program Kerja Praktek di setiap Perguruan Tinggi dipastikan standar prosedurnya berbeda-beda namun secara umum untuk tujuan dan pelaksanaannya sama yaitu agar supaya Mahasiswa dapat terjun langsung kepada masyarakat dan industri untuk mendapatkan pengalaman serta mengimplementasikan ilmu yang mereka dapatkan di perkuliahan. Satu bentuk contoh pelaksanaan Kerja Praktek di Universitas Xyz setiap Mahasiswa akan diarahkan untuk melaksanakan Kerja Praktek ke perusahaan atau instansi pemerintah maupun swasta. Disana mereka dapat melakukan analisis sistem,. (Andrianto \& Wijoyo, 2020)

Permasalahan-permasalahan diatas agar dapat teratasi maka diperlukan revolusi sistem informasi yang bersifat online untuk mengefisienkan waktu dan respon yang cepat. Serta aplikasi yang dapat mempermudah pendataan informasi-informasi Kerja Praktek dan Skripsi di Jurusan Sistem Informasi Fakultas Ilmu Komputer Universitas Al Asyariah Mandar yang dibutuhkan haruslah mudah digunakan dan sesuai dengan standar operasional yang telah ada agar penggunaan tidak membingungkan.(Fatimah, t.t.2012)

Fakultas Ilmu Komputer Universitas Al Asyariah Mandar saat ini masih menggunakan dokumen-dokumen berupa kertas sehingga arsip-arsip yang telah disimpan disuatu tempat berpotensi besar untuk hilang. Selain itu tidak menutup kemungkinan adanya human error pada manajemennya. secara dokumen kertas membutuhkan banyak waktu sehingga respon juga akan membutuhkan waktu yang banyak agar lebih teliti. Belum lagi bila seorang dosen yang bersangkutan berhalangan hadir sehingga proses pendaftaran Kerja Praktek dan Skripsi akan tertunda. Mahasiswa yang mengurus akan merasakan banyak tundaan-tundaan karena beberapa sebab diatas.(Utama, Y, 2011)

Untuk mengatasi permasalahan tersebut maka dirancang Sistem Informasi Pendataan dan Penilaian PKL (Praktek Kerja Lapangan) Mahasiswa Berbasis Web, yang dapat membantu dalam menyelesaikan permasalahan yang dihadapi dalam proses Pendataan dan Penilaian PKL dengan menerapkan teknologi informasi sehingga dapat mempermudah dalam hal Praktek Kerja Lapangan.
Keadaan ini dapat diantisipasi dengan cara yang lebih optimal jika digunakan teknologi informasi dalam bentuk sistem situs web interaktif dan terintegrasi (Qashlim, 2019). Teknologi ini dapat menawarkan cara praktis untuk membantu memberikan solusi alternatif (QAShlim, 2019)

Penelitian terkait yang mempelajari. Desain aplikasi utilitas keluhan dengan metode extreme programming. Metode ini lebih unggul dalam memenuhi kebutuhan perkembangan dan perubahan yang terjadi setiap saat. Selain itu pengembang dan pemangku kepentingan berperan langsung dalam perancangan aplikasi ini.Penelitian terkait sebagaimana dilakukan oleh .(Wahyu Ciptaningrum 2017).

\section{METODE PENELITIAN}

\section{Bahan Penelitian}

Data yang digunakan dalam penelitian ini, data Penilaian PKL (Praktek Kerja Lapangan) Seperti Lembar Penilaian Kerja Praktek Mahasiswa, Penilaian Pembimbing Lapangan Penilaian Instansi Tempat Kerja Praktek.

\section{Kerangka sistem}

Berikut ini kerangka sistem dari Merancang Sistem Informasi Pendataan dan Penilaian PKL (Praktek Kerja Lapangan) Mahasiswa Berbasis Web, untuk menggambarkan tujuan yang ingin dicapai. Dapat dilihat pada gambar 3.2 .

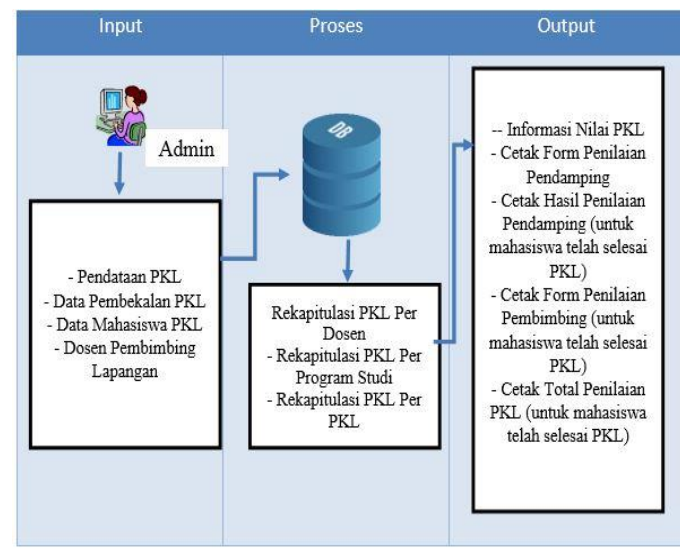

Gambar 1. Kerangka Sistem

Pada kerangka sistem di atas menjelaskan secara bertahap tentang proses yang dilakukan oleh sistem. Proses yang dilakukan oleh sistem adalah sebagai berikut:

1.Admin melakukan penginputan data .

- Pendataan PKL

- Data Pembekalan PKL

- Data Mahasiswa PKL

- Dosen Pembimbing

- Penilaian PKL

- Rekapitulasi PKL Per Dosen

- Rekapitulasi PKL Per Program Studi 


\section{HASIL DAN PEMBAHASAN \\ Hasil perancangan}

Hasil penelitian ini adalah sebuah aplikasi Sistem Informasi Pendataan dan Penilaian PKL (Praktek Kerja Lapangan). menggunakan bahasa pemrograman HTML dan PHP. Pada Sistem Informasi Pendataan dan Penilaian PKL (Praktek Kerja Lapangan). ini menyediakan fitur bagi pengguna di bagian awal tampilan yakni Beranda ,Pendataan PKL,Data Pembimbing,Penilaian PKL,Rekap Bimbingan yang ingin di data lalu di nilai oleh dosen pembimbing lapangan sesui format yang muncul maka akan secara otomatis di alihkan ke menu penilaian jika selesai mengisi data dan melakukan penilaian PKL.

\section{a. Use Case Admin}

User case admin merupakan tampilan menu yang hanya dapat diakses oleh admin terdiri atas Beranda Pendataan PKL Data Pembimbing Penilaian PKL Rekap Bimbingan login. Dalam hal ini yang bertindak sebagai admin terdiri atas dua yakni menu file yang digunakan untuk menampilkan informasi apa yang akan ditampilkan oleh admin sesuai dengan proses yang berlangsung, dan kedua menu penentuan yang digunakan untuk menentukan penilaian mahasiswa serta melihat data sesuai dengan tahapan penilaian yang berlaku.

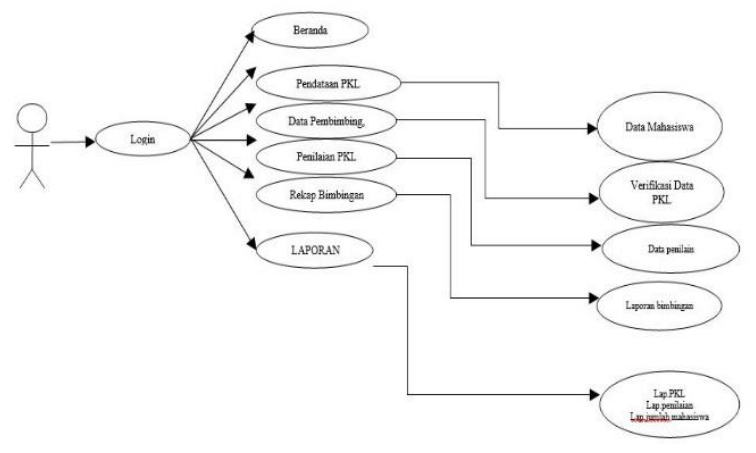

Gambar 4.1 Use Case Admin

\section{b. Use Case User Dosen}

Use case user adalah gambaran alur sistem dimana User dapat mengakses menu yang telah dirancang dalam website,

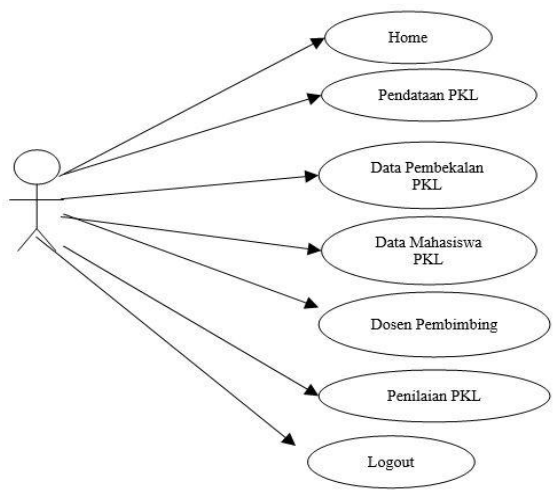

Gambar 4.2 Use Case User
Di atas menjelaskan di mana dosen memberikan penilain terhadap mahasiswa pkl seteleh selesai penilain mahasiswa memasukan atau memilih mahasiswa yang akan di nilai dan melihat laporan pkl mahasiswa dan nama pembimbing lapangan mahasiswa pkl setelah proses tersebut di lakukan makan akan di verifikasi oleh admin dan di rekap laporan penilaian dan pendataan mahasiswa pkl tersebut.

\section{Rancangan Sistem}

Hasil Pengembangan Sistem

a. Form Halaman admin

Form menu adminadalah form yang digunakan untuk mengelolah data dosen data mahasiswa dan rekapan penilain Mahasiswa PKL tersebut yang di tampilkan di sistem, seperti yang terlihat pada gambar 4.1.



Gambar 2. Form Halaman admin

b. Form pendataan Mahasiswa PKL

Form ini adalah form yang digunakan admin dalam melakukan menginputan data mahasiswa yang akan PKL, prosedur di lakukan dengan menulis nama mahasiswa program studi dan melakukan pemilihan sudah pembekalan atau belum pembekalan pada sistem ini seperti terlihat pada gambar 4.2



Gambar 4.2 Form pendataan Mahasiswa pkl

\section{c. Form Pembimbing PKL}

Form ini adalah form yang digunakan dalam menginpuntan data dosen pembimbing lapangan mahasiswa praktek kerja lapangan (PKL) seperti terlihat pada gambar 4.3. 


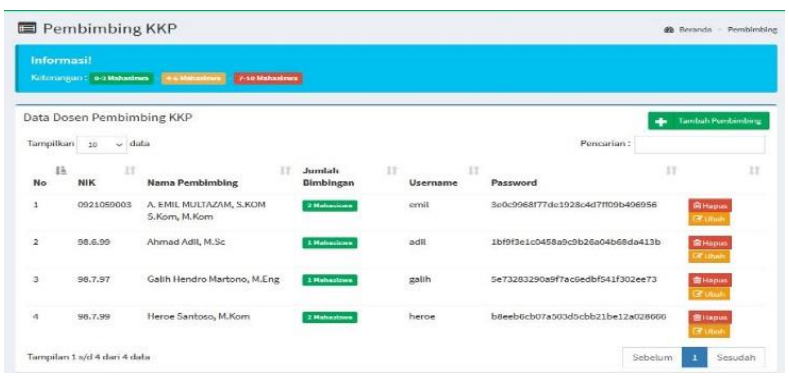

Gambar 4.3 Form pembimbing PKL

\section{d. Form Penilain PKL}

Form admin adalah form yang digunakan admin untuk Inputkan Nilai untuk Form Penilaian Pendamping PKL. Inputkan Nilai untuk Form Penilaian Pembimbing PKL. Terkahir Inputkan Nilai untuk Form Total Penilaian PKL. ke aplikasi seperti terlihat pada gambar 4.4.

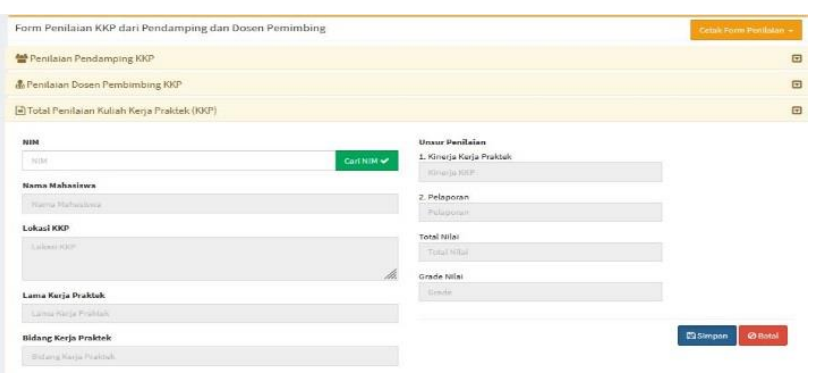

Gambar 4.4 Form Penilaian PKL

\section{h. Form Rekap Bimbingan PKL}

Form halaman rekap bimbingan PKL adalah form yang digunakan admin dalam mengelola ,Data Mahasiswa yang sedang melakukan PKL yang telah terdaftar, Batas lama proses penyelesaian PKL yaitu selama 6 Bulan Status Mahasiswa PKL: Selesai / Belum Selesai / Non Aktif / Mengulang dimana ada beberapa menu di antaranya seperti terlihat pada gambar 4.5.

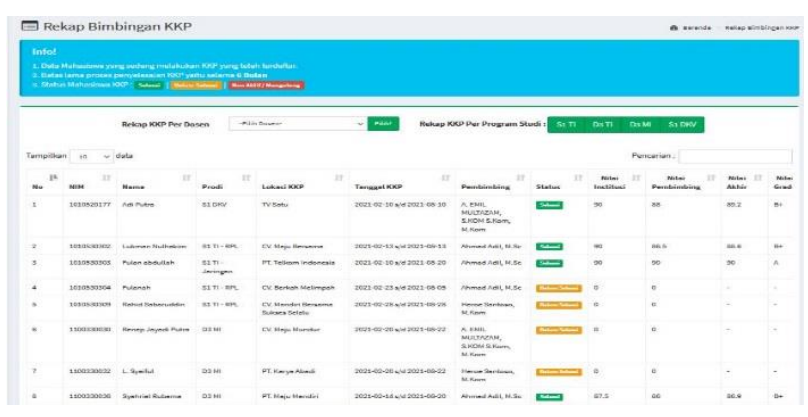

Gambar 4.5 Form Rekap Bimbingan

\section{i. Form halaman Dosen}

Form data dosen ini adalah form yang digunakan dosen melakukan penilaian pendamping penilaian pembimbing rekap bimbingan pkl penilain terhadap pendapingan mahsiswa pkl tersebut seperti terlihat pada gambar 4.6.

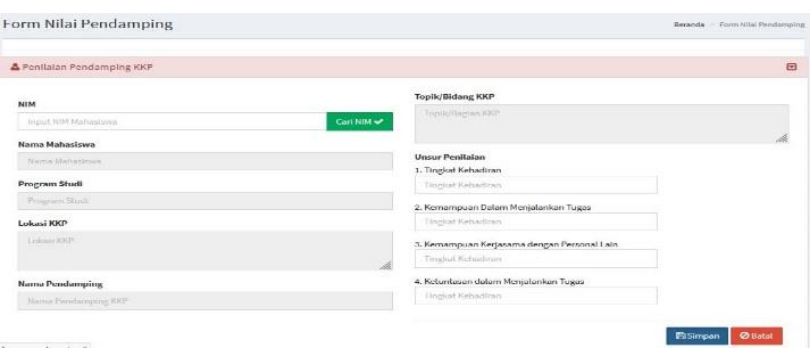

Gambar 4.6. From halaman dosen

\section{g. Form halaman mahasiswa}

Form mahasiswa adalah form yang digunakan mahasiswa melihat data penilaian pkl yang di berikan kepada dosen pembimbing lapangan dimanan mahasiswa dapat mencetak data penilain yang berikan terhadap dosen pembing lapagan tersebut adapun data yang akan di cek mahasiswa seperti cetak form penilaian pendamping untuk mahasiswa yang baru mulai pkl cetak hasil penilaian pendamping untuk mahasiswa telah selesai pkl cetak form penilaian pembimbing untuk mahasiswa telah selesai pkl cetak total penilaian pkl untuk mahasiswa telah selesai pkl seperti yang terlihat pada gambar 4.7



Gambar 4.7 Form halaman mahasiswa

\section{u. Form laporan cetak penilaian}

Form cetak laporan penilaian adalah form yang digunakan mahasiswa dalam mencetak penilain PKL yang telah dilakukan selama PKL oleh siswa seperti yang terlihat pada gambar 4.8



Gambar 4.8 Form rekap laporan PKL 


\section{Uji Coba Sistem dan Program}

Pada pengujian sistem digunakan teknik pengujian dengan pengujian black box dan simulasi aplikasi. Berikut ini adalah hasil pengujian menggunakan uji Blackbox.

\section{Tabel 1. Hasil Pengujian Blackbox}

\begin{tabular}{|c|c|c|c|c|}
\hline No & Pengujian & Hasil yang diharapkan & $\begin{array}{c}\text { Hasil } \\
\text { Pengujian }\end{array}$ & Ket. \\
\hline 1. & Form Login Admin & & & \\
\hline & Button Login & $\begin{array}{l}\text { Jika button login diklik maka } \\
\text { sistem akan mengecek username } \\
\text { dan id sudah cocok, jika ia maka } \\
\text { form menu utama admin akan } \\
\text { tampil, dan jika tidak valid maka } \\
\text { textbox username dan id akan } \\
\text { kosong dan login tidak berhasil. }\end{array}$ & $\begin{array}{l}\text { Sesuai yang } \\
\text { diharapkan }\end{array}$ & OK \\
\hline 2. & $\begin{array}{l}\text { Form Menu Utama } \\
\text { Admin }\end{array}$ & & & \\
\hline & Menu utama & $\begin{array}{l}\text { Jika menu utama diklik maka } \\
\text { akan tampil tampilan menu } \\
\text { dashboard, data siswa, } \\
\text { pengumuman, pendaftaran dan }\end{array}$ & $\begin{array}{l}\text { Sesuai yang } \\
\text { diharapkan }\end{array}$ & OK \\
\hline
\end{tabular}

Tabel 4.2 Tabel Pengujian Blackbox User Pendaftar

\begin{tabular}{|c|c|c|c|c|}
\hline No & Pengujian & Hasil yang diharapkan & $\begin{array}{c}\text { Hasil } \\
\text { Pengujian }\end{array}$ & Ket. \\
\hline 1. & $\begin{array}{l}\text { Form Informasi } \\
\text { Batas } \\
\text { Pengumpulan } \\
\text { Berkas PKL }\end{array}$ & $\begin{array}{l}\text { From menu utama user di mana } \\
\text { from ini jika di klik akan } \\
\text { muncul berkas pkl }\end{array}$ & & \\
\hline & $\begin{array}{l}\text { Form Notification } \\
\text { H-1 dan H-7 } \\
\text { Pengumpulan } \\
\text { Berkas PKL }\end{array}$ & $\begin{array}{l}\text { Jika Form Notification Diklik } \\
\text { Maka Akan Muncul Informasi } \\
\text { Pengumpulan Berkas PKL }\end{array}$ & $\begin{array}{l}\text { Sesuai yang } \\
\text { diharapkan }\end{array}$ & $\mathrm{OK}$ \\
\hline & $\begin{array}{l}\text { Cetak Hasil } \\
\text { Penilaian } \\
\text { Pendamping (untuk } \\
\text { mahasiswa telah } \\
\text { selesai PKL) }\end{array}$ & $\begin{array}{l}\text { Jika form Penilaian klik maka } \\
\text { akan muncul mahasiswa telah } \\
\text { selesai PKL) }\end{array}$ & $\begin{array}{l}\text { Sesuai yang } \\
\text { diharapkan }\end{array}$ & $\mathrm{OK}$ \\
\hline
\end{tabular}

\section{SIMPULAN}

Berdasarkan hasil penelitian dari awal hingga berdasarkan hasil penelitian yang telah dilakukan mulai dari awal hingga proses pengujian terhadap aplikasi sistem informasi pendataan dan penilaian pkl praktek kerja lapangan maka dapat diberikan kesimpulan yaitu dengan adanya sistem informasi pendataan dan penilaian pkl praktek kerja lapangan ini dapat memberikan kemudahan pendataan dan penilaian pkl (praktek kerja lapangan mahasiswa dapat mempermudah akademik dalam mengelola data $\mathrm{pkl}$ penilaian dan rekapitulasi $\mathrm{pkl}$ mahasiswa. Aplikasi juga dapat mempermudah dosen dalam menginputan nilai pkl dan memudahkan mahasiswa dalam mencetak form pkl dan melihat nilai pkl

\section{DAFTAR PUSTAKA}

Andrianto, S., \& Wijoyo, H. (2020). Rancang Bangun Sistem Informasi Siswa Berbasis Web di Sekolah Minggu Buddha Vihara Dharmaloka Pekanbaru. TIN: Terapan Informatika Nusantara, 1(2), 83-90.

Qashlim, A., Nurtanio, I., Ilham, A. A., \& Ilham, A. (2019, March). Estimation of milkfish physical weighting as Fishery Industry Support system using image processing technology. In Journal of Physics: Conference Series (Vol. 1175, No. 1, p. 012029). IOP Publishing.

Chandiarie, C., Rostianingsih, S., Setiabudi, D. H., Studi, P., Infromatika, T., Industri, F. T., Petra, U. K., \& Siwalankerto, J. (2018). Perancangan dan Pembuatan Website E-Commerce Penjualan Spare part UD. Cahaya Agung Motor. Jurnal Infra Petra.

Fatimah, S. (t.t.)2012. Diajukan untuk memenuhi salah satu syarat nilai kuliah PKL Program Diploma Tiga (D.III). 90.

Lyony, D. (2013). Sistem Informasi Persedian Suku Cadang Pada Bengkel Borneo Motor Semarang. Skripsi, Fakultas IImu Komputer, 5.

Makmur, T. (2019) Teknologi Informasi. Info Bibliotheca: Jurnal Perpustakaan Dan Ilmu Informasi 65-74. https://doi.org/10.24036/ib.v1i1.12

Muhammad Rangga Perkasa, Asep Deddy, P. (2014). Perancangan Aplikasi Penjualan Sparepart Pada Bengkel Fajar Motor Menggunakan Metode Berorientasi Objek. Jurnal Algoritma, 11(1), 1-7.

Putri, S. H., \& Mulyono, H. (2017). Analisis Dan Perancangan Sistem Informasi Penjualan Berbasis Web (Studi Kasus: UD. Cakra Motor). Jurnal Manajemen Sistem Informasi, 2(4), 821-830.

Setiyono, a. (2013). Perancangan sistem informasi penjualan sepeda motor honda berbasis web pada dealer pt. Nusa motor ponorogo. 1-110.

Utama, Y. (2011). Sistem informasi berbasis web jurusan sistem informasi fakultas ilmu komputer universitas sriwijaya. JSI: Jurnal Sistem Informasi (E-Journal), $3(2)$.

Wahyu Novianto, Y. S. (2016). Analisa dan perancangan sistem informasi bengkel pada bengkel lancar motor. 